\title{
Analysis of micro-climate for the scheme of green infrastructure regeneration in Jeonju
}

\author{
K. Park, C. Choi \& H. Park \\ Department of Civil and Environmental Engineering, KAIST, Korea
}

\begin{abstract}
The purpose of this study is to carry out a micro-climate analysis before and after applying Green Urban Block System (GUBS) for urban infrastructure regeneration to analyze a differential of wind flow and thermal environment, and thereby to quantitatively estimate its effectiveness. "Green Urban Block System", including green technologies for urban infrastructure is to maximize the resource recycling, to improve the efficiency and to connect every environmental infrastructure associated with water, waste and energy at urban block unit. GUBS has an easy applicability because it is designed to be installed block by block in a field whereas building a large, centralized system for urban infrastructure regeneration requires an enormous initial capital investment. To implement the micro-climate analysis, various data such as land use, topography, height and materials of building, and weather conditions are collected. The results of micro-climate analysis are estimated by the outputs of fluid simulation for pathway of cold wind and thermal variation. There are three programs for green urban regeneration in Jeonju: the river restoration project, traditional market revitalization project, and eco-school project of Jeonju Primary School. These programs are implemented not only to maximize the resource recycling but also to revitalize the urban core. The results of micro-climate analysis are as follows. The height from the ground level of cold wind was much elevated, and the wind speed increased up to $0.12 \mathrm{~m} / \mathrm{s}$ due to the expansion of waterfront space and grassland through three programs. Therefore, the temperature at the ground level dropped to $1.62^{\circ} \mathrm{C}$. Based on these results, it was found that the three programs for green urban regeneration improved the urban environment of wind and temperature at ground level and are capable of reducing the urban heat island and might mitigate the energy consumption at an urban core.

Keywords: urban infrastructure regeneration, micro-climate, Green Urban Block System.
\end{abstract}




\section{Introduction}

Ecological environment is critical for humans because, it is directly related to their survival and provides raw materials for every human development. However, our economic and social development has already caused serious damage to the environment, threatening sustainable development. Our ecological environment of the city plays an important role not only in human survival but also in socio-economic development. The concept of eco-city came into being, it is affordable in the city within the ecological, the use of the principle of sustainable development and the basic principles of ecological economics, urban economic way of promoting change from the point of view, in order to improve the city environmental quality for the purpose of seizing the city's main line of the industrial structure adjustment of the layout to play the city's resources, through overall planning and promote the comprehensive development of the city's ability to achieve sustainable socio-economic development (Song [1]).

In this paper, it is to do a micro-climate analysis before and after applying Green Urban Block System (GUBS), which is considered one of the most economical technologies for urban infrastructure regeneration, to analyze a differential of wind flow and thermal environment, and thereby to figure out a quantitative estimation of its effectiveness.

\section{System configuration}

\subsection{GUBS (Green Urban Block System)}

The GUBS is designed to renovate the conventional urban infrastructure into the resource-recycled infrastructure for a sustainable city to achieve green growth by mitigating carbon emission and environmental pollution, as shown in the Figure below. This system in which water, waste and energy are almost totally reused and circulated within the complex is applied to the whole urban areas to optimize the use of resources and eventually to contribute to the community's green growth (Kiyong Park et al. [2], Patsy [3]).

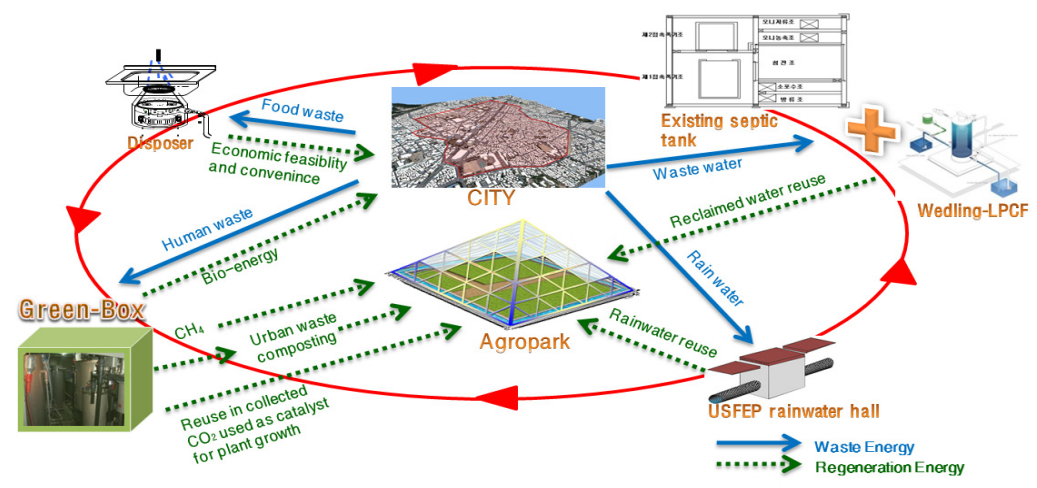

Figure 1: Material and energy flow of GUBS. 


\subsection{UMcMS (Urban Micro-climate Management System)}

The Urban Micro-climate Management System (UMcMS) is a general technology for maintaining and operating urban convenience that can control and manage the integrated environment of heat and wind on the whole process of urban development and urban regeneration projects. As shown in Figure 2, Graphic User Interface (GUI) conducts database generating, simulation set-up, analyses-results representation and evaluation in order, while taking account of usability and efficiency.

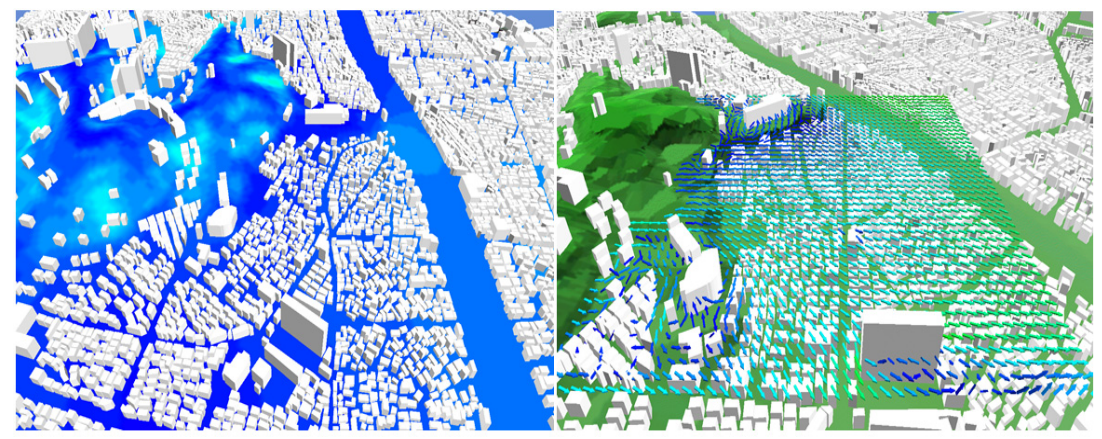

Figure 2: GUI; graphic user interface.

\section{Field application}

The river restoration project is to safely maintain water quality and to use the reclaimed water as the urban streams by refreshing rainwater and sewage as shown in Fig. 2. Traditional market revitalization project intends to construct artificial waterway using the urban stormwater from the emerging downtown to suburban market to gather people and revitalize the degraded areas as shown in Fig. 4 (Park et al. [4]).

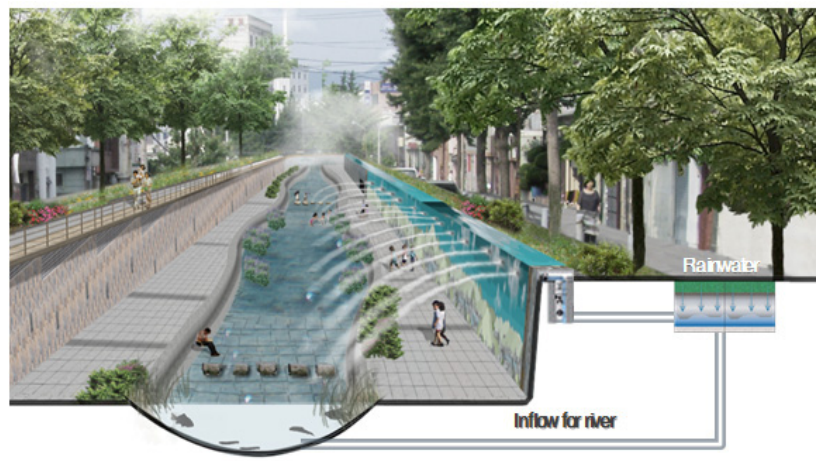

Figure 3: River restoration project. 


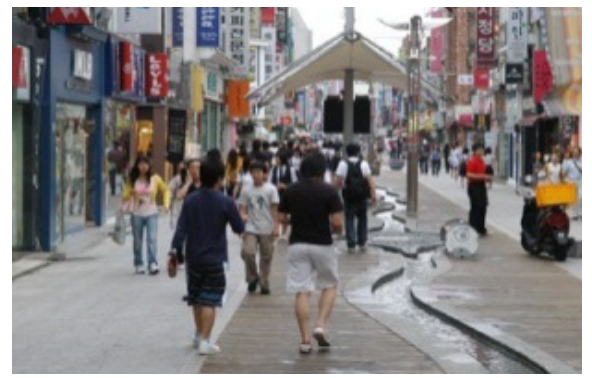

Figure 4: Traditional market revitalization project.
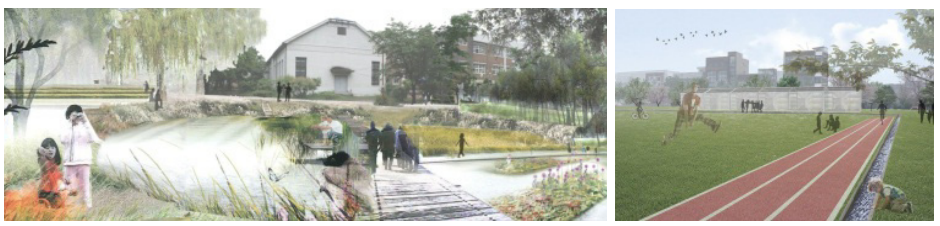

Figure 5: Eco-school project of Jeonju Primary School.

The eco-school project of Jeonju Primary School aims to reuse food waste, rainwater and underground water released from school, and then turns them into recycled resources such as recycled water and fertilizer for school forest.

\section{Micro-climate analysis and benefit}

To implement the micro-climate analysis, various data such as land use, topography, height and materials of building, and weather conditions were collected and stored. Therefore, the result of micro-climate analysis was estimated from the outputs of fluid simulation for pathway of cold wind and thermal variation. While putting the wind directions to target area of top priority, 7 core points are set up for each micro-climate analysis before and after urban regeneration projects.
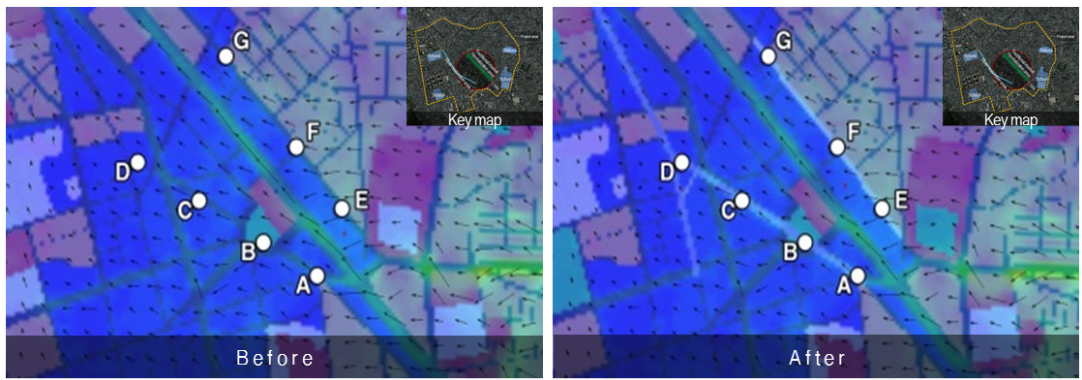

Figure 6: Thermal variation analysis. 
According to the results of cold wind analysis for two projects-river restoration project and traditional market revitalization project, cold wind velocity shows a significant improvement going from the South to the North, but cold wind thickness has no distinct difference. River restoration project and artificial waterway projects start at Point A and E, respectively, so cold wind velocity shows clear improvement as it goes to Point D and G.

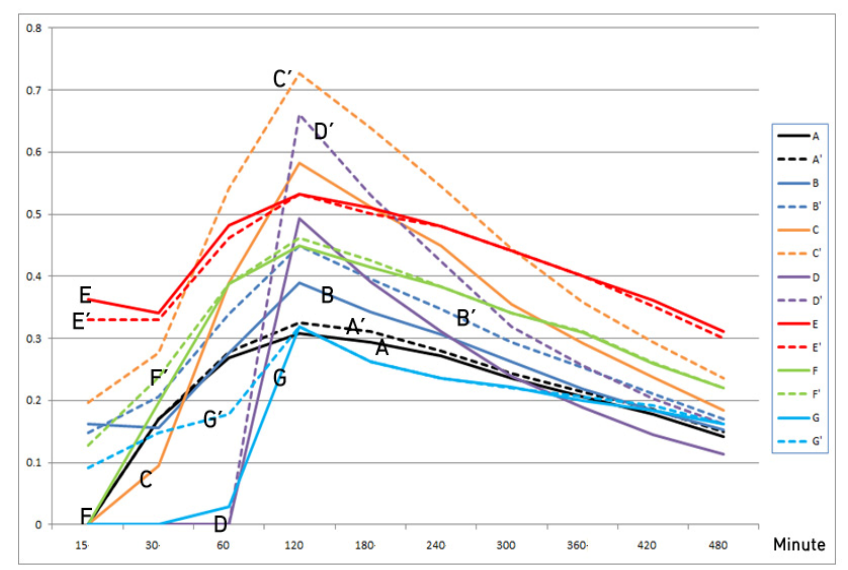

Figure 7: Changes in cold wind velocity.

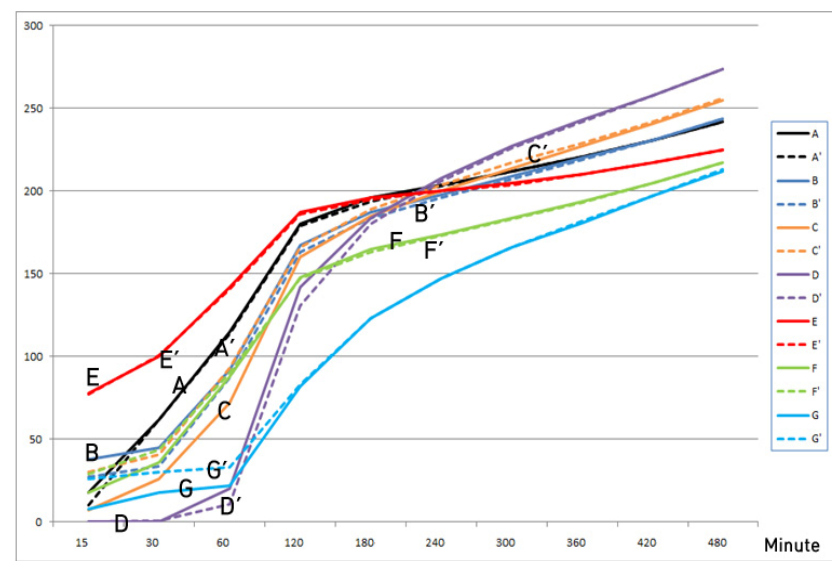

Figure 8: Height variation of cold wind.

According to the results of thermal environment analysis for river restoration project, the heat is down $1.62^{\circ} \mathrm{C}$, a drop of more than $0.2^{\circ} \mathrm{C}$. Traditional market revitalization project decreases the heat by more than $0.1^{\circ} \mathrm{C}$. The total area where the heat falls account for nearly 70 to $80 \%$, meaning an advantage of deceasing the heat through those projects. 


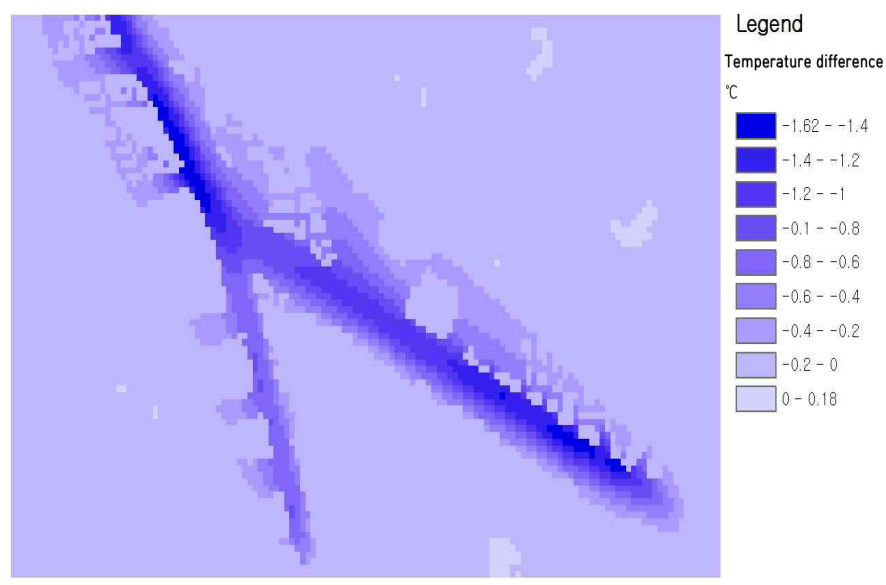

Figure 9: Thermal environment.

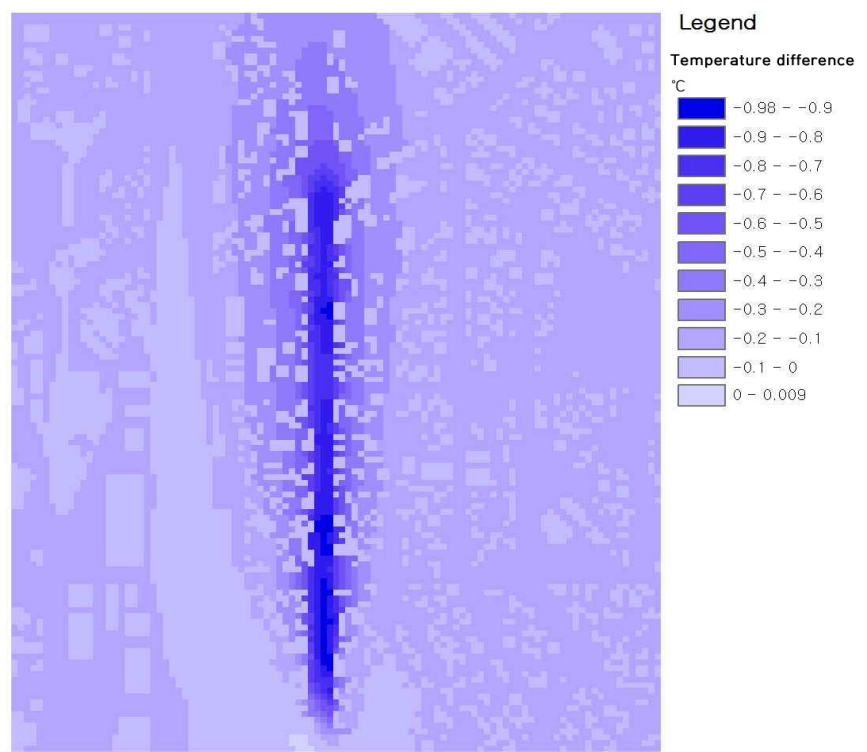

Figure 10: Thermal environment. 

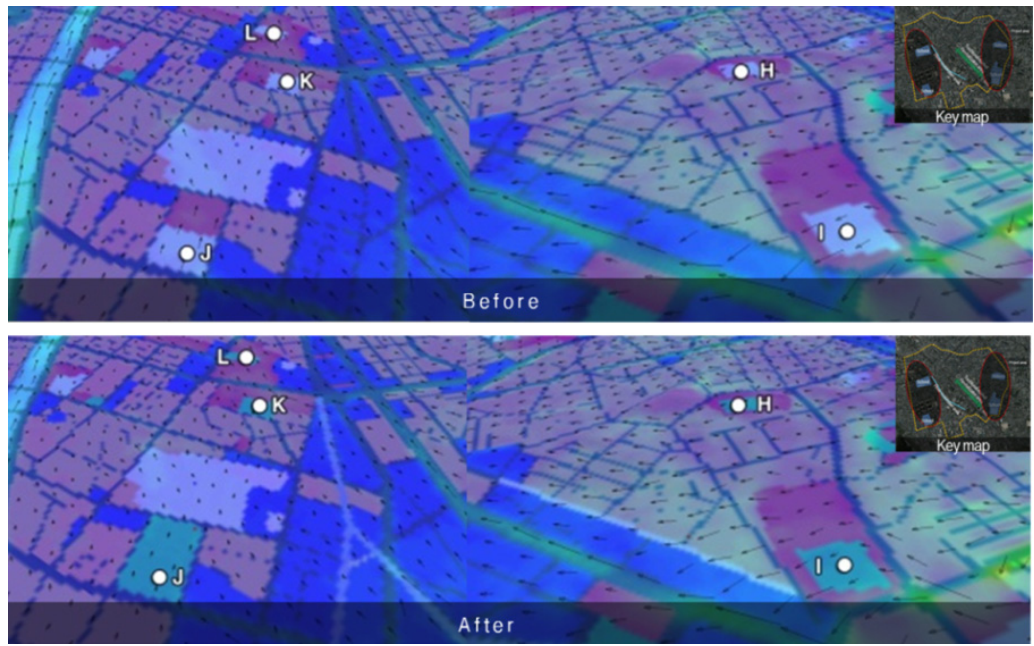

Figure 11: Thermal variation analysis.

According to the results of cold wind analysis for Eco-school project of Jeonju Primary School, the velocity of cold wind gets slow as shown in Fig. 12, but the cold wind gets thickened as shown in Fig. 13. The microclimate might seem worsening only with the cold wind velocity, but the thickened cold wind means the large amount of fresh air is centering on the target area and becomes the original source of cold wind. Therefore, the project is expected to serve as a cool island having balmy air.

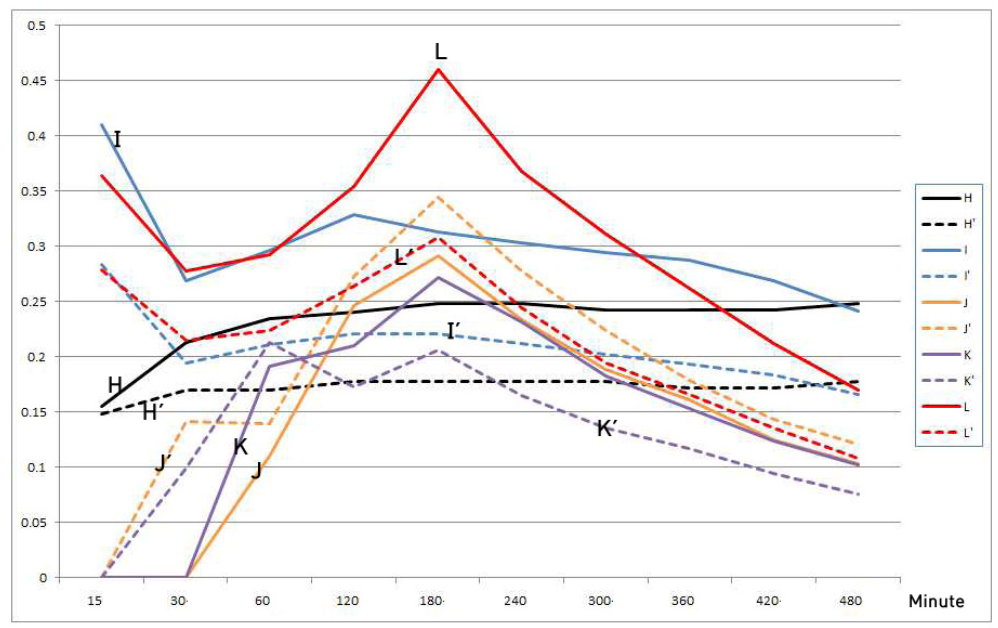

Figure 12: Changes in cold wind velocity. 


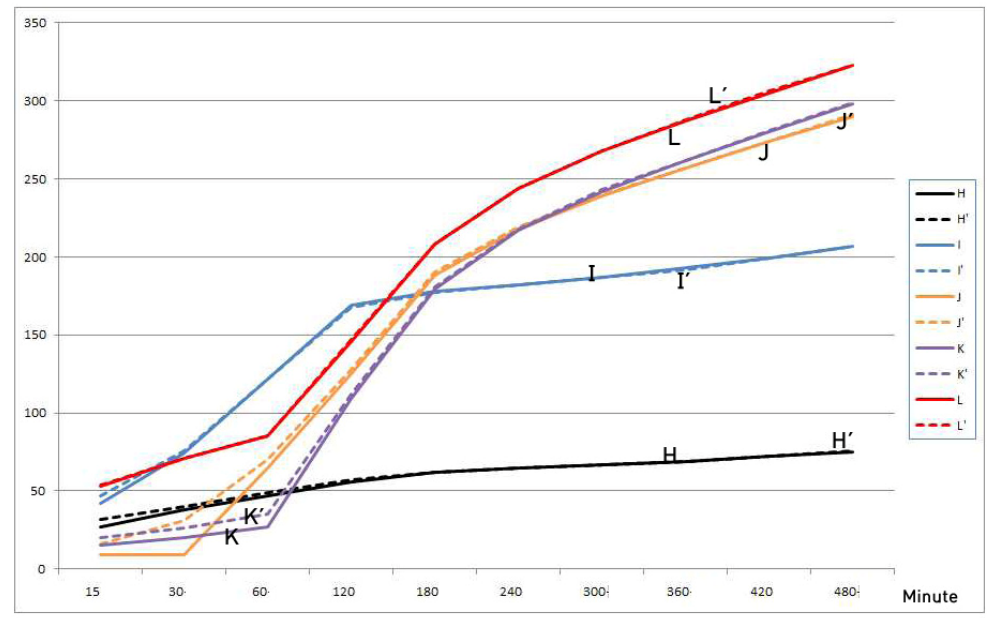

Figure 13: Height variation of cold wind.

\section{Conclusion}

The purpose of this study is to carry out a micro-climate analysis before and after applying Green Urban Block System (GUBS) for urban infrastructure regeneration to analyze a differential of wind flow and thermal environment, and thereby to quantitatively estimate its effectiveness.

The results of micro-climate analysis are as follow. The height from the ground level of cold wind was much elevated, and the wind speed increased up to $0.12 \mathrm{~m} / \mathrm{s}$ due to the expansion of waterfront space and grassland through three programs. Therefore, the temperature at the ground level dropped to $1.62^{\circ} \mathrm{C}$. Based on these results, it was found that three programs for green urban regeneration improved the urban environment of wind and temperature at ground level and are capable of reducing the urban heat island and might mitigate the energy consumption at an urban core.

\section{Acknowledgement}

This research was supported by a grant (07-UR-BO4) from High-tech Urban Development Program funded by Korea Ministry of Land, Transport and Maritime Affairs.

\section{References}

[1] Song Y., Ecological city and urban sustainable development, International Conference on Green Building and Sustainable Cities, 142-146, 2011. 
[2] Kiyong Park, Changkoo Choi, Heekyong Park, Amenity enhanced apartment complex design using reclaimed water and renewable energy, Conference of International Water Week, 2010.

[3] Patsy H., The institutional challenge for sustainable urban regeneration, Cities, Vol. 12, No. 4, 221-230, 1995.

[4] Park W., Choi C., and Park H., Development of water reuse system for urban public use by membrane bioreactor and coagulation-lifted pore control fiber filter, Conference of Korean Society on Water Quality, 149-150, 2009. 